\title{
A Educação das relações étnico- raciais e a Sociologia da Infância: contribuições da arte africana para iniciar as rodas de conversa
}

\section{Edmilson dos Santos Ferreira}

Doutorando em Educação - Programa de Pós-graduação em Educação da Universidade Federal do Rio de Janeiro (PPGE/UFRJ), mestre em Educação Universidade Católica de Petrópolis, Técnico em Assuntos Educacionais da Escola de Educação Infantil (EEI-UFRJ)

\section{Deise Marins Alcântara}

Licenciada em Artes Visuais - Universidade do Estado do Rio de Janeiro (UERJ), Rio de Janeiro, Brasil. Professora substituta da Escola de Educação Infantil da Universidade Federal do Rio de Janeiro (EEI-UFRJ).

\section{Danielle Minioli Ferreira}

Licenciada em Pedagogia - Universidade Federal Rural do Rio de Janeiro (UFRRJ), Rio de Janeiro, Brasil. Professora de Educação Infantil da Secretaria Municipal de Educação do Rio de Janeiro (SME-RJ)

\section{Resumo}

Este trabalho tem por objetivo identificar as estratégias adotadas na prática docente em Educação Infantil acerca da Educação das Relações Étnico-raciais na escola na perspectiva de Lei 10.639/2003. Apresentamos algumas ações e propostas vivenciadas na Escola de Educação Infantil da Universidade Federal do Rio de Janeiro (EEI-UFRJ). A pesquisa aponta para uma demanda por um processo de formação continuada que privilegie a articulação entre teoria e prática.

Palavras-chave: relações étnico-raciais; educação infantil, Sociologia da Infância;

\section{Abstract}

This work aims at identifying the strategies applied at teachers' practice in preschool about education with ethnic-racial relations in the school from the perspective of Law 10.639/2003. Present some proposals and actions experienced at Escola de Educação Infantil at Universidade Federal do Rio de Janeiro (EEI-UFRJ). The research pinpoints to a demand for continuous teaching training which praises the relationship between theory and practice.

Keywords: ethnic-racial relations, Preschool Education, Sociology of Childhood

\section{Resumen}

Este trabajo tiene como objetivo identificar las estrategias aplicadas en la práctica de los docentes en preescolar acerca de la educación de las relaciones étnico y raciales en la escuela desde la perspectiva de la Ley 10.639 / 2003. Presentamos algunas propuestas y acciones con una experiencia en la Escola 
de Educação Infantil da Universidade Federal do Rio de Janeiro (EEI-UFRJ). La investigación señala a una demanda de un proceso de formación docente continua que favoreszca a la relación entre la teoría y la práctica.

Palabras Ilaves: Relaciones étnico y raciales, Educación Infantil, Sociología de la Infancia

\section{Para inicio de conversa...}

A infância constitui uma categoria social como uma particularidade da consciência infantil. O historiador Philippe Ariès (1981) contribui significativamente para esta compreensão ao apontar os séculos XVI e XVII como uma concepção de infância centrada na "inocência e na fragilidade infantil". Enquanto o século XVIII configurou a construção de uma infância moderna, baseada nos ideais de liberdade, autonomia e independência. Na Europa, no século XIX, as crianças que viviam nas cidades, a partir dos três anos, aproximadamente, já podiam participar das mesmas atividades dos adultos, os cuidados especiais eram reservados apenas aos primeiros anos de vida e às crianças que tinham melhores condições sociais e financeiras.

Ariès (1981) nos faz perceber que as concepções de infância trazem consigo diferentes contextos econômicos, geográficos e sociais demarcados pelo tempo histórico e as condições socioculturais em que as crianças se encontram. Nesta direção, as concepções de infância estão em constantes processos de construção e transformação.

Ao analisarmos o sentimento de infầncia de Ariès, observamos uma infância que privilegia os seus modos de ser, pensar e agir e, portanto, merece um olhar mais atento, pois se evidencia que seus achados "favorecem a interpretação de que essas camadas sociais teriam monopolizado a condução do processo de promoção do respeito à criança" (KUHLMANN Jr., 1998, p. 24).

Sua pesquisa focaliza-se em fontes de famílias abastadas, principalmente, a partir da educação de meninos, entretanto, deixa à margem as fontes históricas populares considerando os poucos registros devido as suas precárias condições econômicas. Nesse sentido, cuidar das crianças ou a preocupação com a sua educação tornou-se uma das responsabilidades das mulheres nessa sociedade que emergia.

Convém destacar que as crianças de classes populares também possuíam proteção, mesmo que não fosse, prioritariamente, pela família: "se é difícil encontrar registros das classes populares, há um amplo conjunto de documentos no âmbito da vida pública, envolvendo as iniciativas destinadas ao atendimento aos pobres e aos trabalhadores" (KUHLMANN Jr., 1998, p. 25).

As atuais reflexões sobre concepções de infância afirmam que as crianças precisam ser consideradas como sujeito histórico e social porque a infância representa um período singular e significativo da vida, portanto:

"É preciso considerar a infância como uma condição da criança. O conjunto de experiências vividas por elas em diferentes lugares históricos, geográficos e sociais é muito mais do que uma representação feita por adultos sobre esta fase da vida. É preciso conhecer as representações da infância e considerar as crianças concretas, localizá-las nas relações sociais, etc., reconhecê-las como produtoras de história" (idem, p. 31). 
"A inflexão proposta pela sociologia da infância permitiu-se pensar a criança como sujeito e ator social de seu processo de socialização, e também construtora de sua infância, de forma plena, e não apenas como objeto passivo desse processo e/ou de qualquer outro. A partir dessa primeira inflexão, outras foram realizadas e, dessa forma, surgiram novas temáticas, bem como a elaboração de novas metodologias que buscaram entender as crianças como produtoras de culturas, a partir delas próprias" (ROSEMBERG \& OLIVEIRA, 2012, p.49).

Nesse sentido, a concepção de infância que defendemos representa-se pelas mudanças que ocorrem nas diferentes formas de organização da sociedade que se reúnem em classes sociais distintas no que se refere à infância e a criança.

Apresentamos este estudo em três partes que se complementam. Na primeira parte, discutimos a Educação Infantil como direito da criança de acordo com os documentos oficiais. Na segunda parte, apresentamos as dimensões éticas e estéticas da arte africana pelo olhar de Pablo Picasso como força de suas tradições e elegemos a Sociologia da Infância como campo de reflexão para interpretar as crianças em sua dimensão identitária na educação das relações étnico-raciais. E finalizamos com algumas possibilidades de organização do processo formativo do trabalho docente para refletir sobre a temática da diversidade com as crianças.

\section{A Educação Infantil no Brasil contemporâneo}

Dentre os caminhos possíveis para discutirmos sobre a Sociologia da Infância, optamos por refletir sobre a Educação Infantil como direito. Assegurar os direitos sociais, especialmente, os direitos das crianças para que elas se desenvolvam em suas múltiplas linguagens requer proteção e financiamento.

O Estado não tinha políticas públicas que pudessem intervir nas escolas infantis, o que dificultava a orientação pedagógica, política e social que as creches e pré-escolas deveriam oferecer. Com os movimentos políticos desencadeados que culminaram com a Constituição de 1988, foram estabelecidos direitos específicos às crianças, principalmente, o direito de inserção às creches e pré-escolas da criança de 0 a 6 anos de idade (CAMPOS, ROSEMBERG \& FERREIRA, 1995).

Entretanto, o Estatuto da Criança e do Adolescente (1990), protege a criança como sujeito de direito à vida, à saúde, à cultura e à educação. E a promulgação das Diretrizes Curriculares Nacionais de 1996, cuja competência é do Ministério da Educação, possibilitaram inúmeros reconhecimentos, da criança e do adolescente principalmente no âmbito pedagógico. É importante ressaltar que não basta ampliar o acesso, mas também aprimorar a formação de professores para que atendam as especificidades da educação infantil.

A participação da mulher no mercado de trabalho brasileiro a partir dos anos 1970, a luta pelos movimentos sociais e a necessidade de ampliação do atendimento as crianças e as lutas pelo direito à educação alicerçada pelo Estatuto da Criança e do Adolescente (ECA) de 1990 e pela Lei de Diretrizes e Bases da Educação Nacional, Lei no 9394/96 contribuíram para definir a educação infantil como dever do Estado. Apesar da fragmentação entre dois segmentos 0-3; 4-6 anos (Emenda Constitucional no 53/2006), não necessariamente no processo educativo, mas do ponto de vista da 


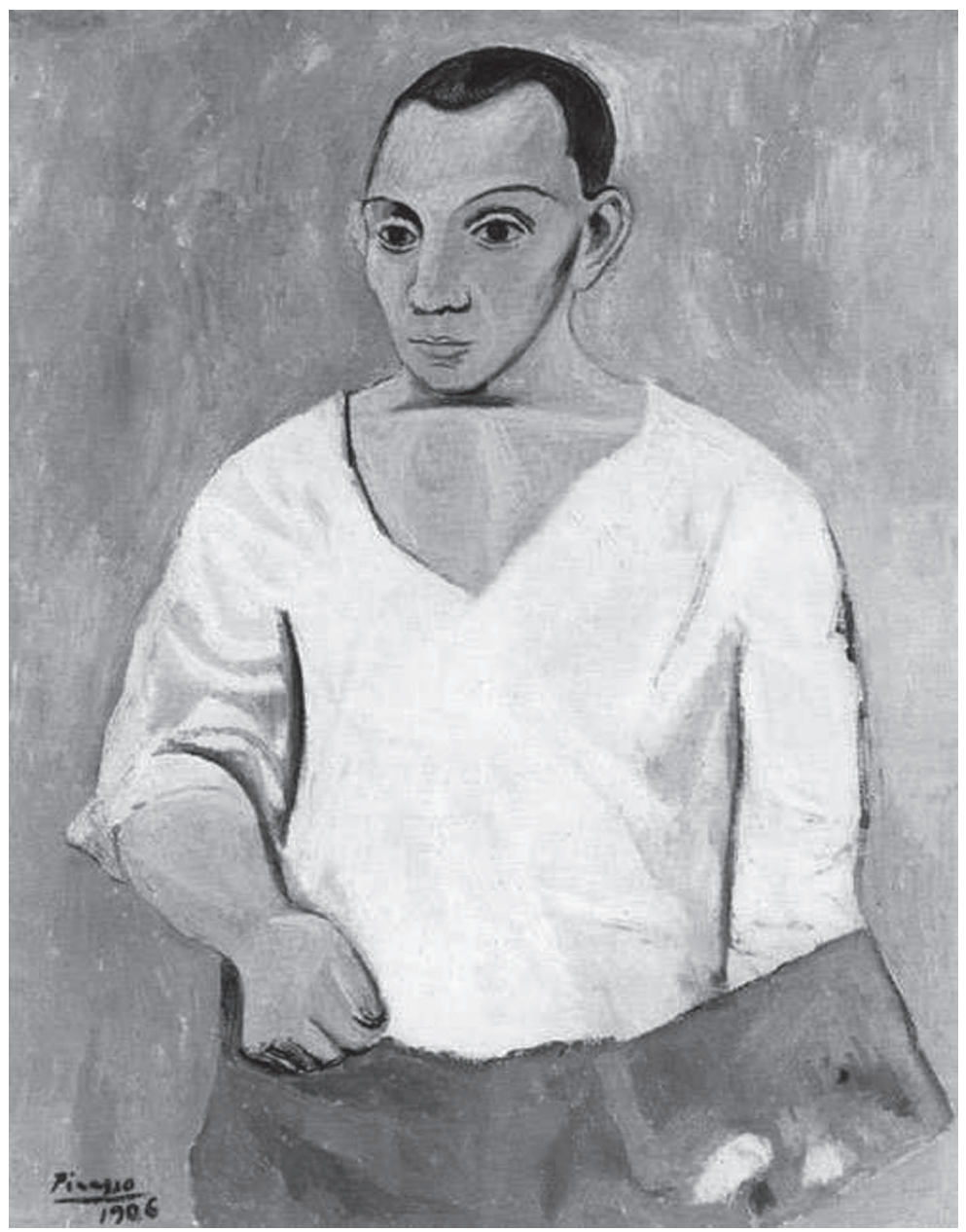

Pablo Picasso, Auto-retrato com paleta, 1906, óleo sobre tela, 92x73cm. Philadelphia Museum of Art, Colecção Albert E. Gallatin.

obrigatoriedade, a Lei no 11.700/2008, assegura o acesso à escola pública de educação infantil, mas próxima de sua residência.

Esse corte etário estabelece a matrícula compulsória na educação básica das crianças a partir da idade pré-escolar e amplia a abrangência dos programas de atendimento à primeira infância (Emenda Constitucional no 59/2009). Dessa forma, espera-se que as redes públicas e escolas implementem o atendimento com equipamento específico para essa faixa etária e gradativamente amplie a oferta em horário integral às crianças de 0-3 anos, tendo em vista o cumprimento do Plano Nacional Educação (PNE) Lei no 13005/2014. De acordo com as orientações do PNE, a Meta 1 determina a universalização do atendimento às crianças de 4-5 anos até 2016. E ainda estabelece a ampliação em 50\% do atendimento às crianças de 0-3 anos (BRASIL, 2014).

\section{Arte africana pelo olhar de Pablo Picasso}

No século XX os artefatos africanos passaram a ser denominados objetos de arte. Portanto, a alteridade emerge como tema inescapável e, para os artistas modernos, esses objetos surgem como fator de provocação e redirecionamento dos processos criativos. É nesse momento que a arte africana torna-se fator considerável no desenvolvimento da arte moderna. 
Ao elevar esses objetos ao status de arte a partir de sua entrada no museu - ou seja, com as atribuições de significados que sua presença no museu legitima-se e estabelece uma narrativa conciliatória de tradições antes apartadas. Abre-se um novo olhar sobre o outro antes percebido como primitivo - no sentido mais insidioso que a palavra confere.

Essas produções passaram a ser recebidas como afirmação de força identitária unificadora, possuindo valor enquanto peça de exibição, tanto pelos artistas da época como Henri Matisse e Pablo Picasso, quanto pelos fruidores e colecionadores de arte.

Contudo, o estético não deve ser visto como uma essência dos objetos. As tradições africanas, como as máscaras, combinam produções de caráter mais realista e outra de natureza mais abstrata e por isso essas tradições não devem ser vistas com foco na religião. A tendência é uma visão que permita uma abordagem multidimensional das representações e interpretações.

\section{A dimensão identitária da criança negra}

De acordo com Abramowicz \& Oliveira (2012), a partir da década de 90 foi possível perceber que a desigualdade afeta diretamente a educação brasileira, onde está intrinsecamente ligada à cor da pele. Nesta direção,

"A pobreza impacta a criança negra de maneira mais cruel e contundente do que a criança pobre branca, já que a familia negra vive com mais intensidade a desigualdade social. Mas não é só isso, a pobreza é atravessada pela raça, o que significa que a raça é também explicativa da pobreza" (p. 50).

Essa dualidade entre raça e questão social está intimamente entrelaçada no discurso do preconceito de classe. Fernando Rodrigues (1995) traz uma discussão do Racismo cordial que existe no Brasil, onde as pessoas negam ter, mas demonstram em pequenas atitudes que são reforçadas porque ainda há um enraizamento da classificação racial a partir da cor da pele (ABRAMOWICZ \& OLIVEIRA, 2012). Nessa mesma dinâmica de relações raciais há um conceito contemporâneo de branquitude que para Liv Sovik (2009) é entendido como: "atributo de quem ocupa um lugar social no alto da pirâmide, é uma prática social e o exercício de uma função que reforça e reproduz instituições, é um lugar de fala para qual uma certa aparência é condição suficiente" (p. 50).

Sovik assinala que a branquitude é um ideal estético e social que valoriza a cor da pele, a fisionomia, o tipo de cabelo; onde ser branco não depende da sua cor, mas do seu status social, pois a prática branca se impõe no contexto sociocultural. Portanto, há uma relação complexa, que envolve um discurso, permeado de afetos, travestida muitas vezes pelo discurso da mestiçagem que nega a existência dos negros e esconde a existência de brancos, implícito no discurso de que "somos todos iguais". O que caracteriza a hegemonia de uma cultura branca e de etnia europeia, onde "o valor da branquitude se realiza na desvalorização do ser negro e ela continua sendo uma medida silenciosa de quase brancos, como dos negros" (p. 53).

O trabalho de Abramowicz \& Oliveira (2012) reconhece que crianças a partir de quatro anos conseguem perceber as nuances entre brancos e negros na sociedade e, portanto, oferece atribuições positivas e negativas sobre suas características. A 
diferença toma corpo, quando a sociedade ocidental institui um padrão que está no outro e não em si.

"Assim, a socialização que se inicia na familia e se amplia com o convivio escolar, ao invés de ser uma experiência positiva no desenvolvimento da criança negra, acaba sendo um fator negativo na constituição de sua autoimagem. E o silêncio que envolve a questão racial nas diversas instituiçôes sociais favorece que se entenda a diferença como desigualdade, como desvio, como anormalidade" (p. 56).

Nesse sentido, a escola sem perceber institui a desigualdade e a diferença quando seleciona os brinquedos e observamos a ausência de bonecas negras ou simplesmente não explora os momentos de estranhamento que se manifestam nas suas brincadeiras.

O preconceito existe na sociedade, no entanto, partimos de levantes positivos também. Ao mesmo tempo em que o discurso racista está à tona na sociedade, o sujeito não é apenas alguém que recebe a ação, mas também são atores sociais que estão a todo o momento participando das interações com a sociedade.

O conceito de Stuart Hall (2003) sobre a diáspora contribui significativamente para esta análise, os negros quando chegaram ao Brasil traz consigo uma carga de saberes, costumes, valores, religiosidade, políticas, linguagens que interferem diretamente a sociedade vigente. Nesta direção, as múltiplas identidades que entram em contato e se atravessam em busca de dialogo. Comunidades culturais diferentes que convivem, tentam construir uma vida comum; ao mesmo tempo em que enriquecem a cultura, também produzem conhecimento, o que influencia a cultura local.

Há uma demanda da própria cultura em rever seu próprio sistema, uma negociação com a "diferença do outro". Portanto, por mais que o Estado Liberal tenha seu caráter universalista da cultura ela é abalada (reinventada/interpretada) em constantes movimentos (inacabados).

"As comunidades migrantes trazem as marcas da diáspora da 'bibridização' e da différance em sua própria constituição. Sua integração vertical e suas tradições de origem coexistem como vínculos laterais estabelecidos com outras 'comunidades' de interesse, prática e aspiração, reais e simbólicos" (HALL, p. 79, 2003).

A busca por uma identificação se faz necessária para o próprio sentimento de pertencimento. Segundo Carvalho e Passos (2008), a diáspora tem uma dinâmica também de reinventar espaços, valores, como a hibridização das práticas religiosas que, nesse emaranhado e complexa negociação, se confundem, se fundem e coexistem. E é visando fortalecer essas memórias e identidades que se busca a valorização de uma África latente no povo brasileiro. Para Canclini (2000), reinventar esses espaços é promover interligações socioculturais, onde o tradicional e o moderno se misturam. Nesse processo de hibridação, que abrange não somente o sincretismo ou a miscigenação, mas as diversas relações interculturais que se fundem também nas formas modernas e em movimentos simbólicos tradicionais.

Falar de racismo no Brasil é algo complexo, pois envolve vários setores sociais, culturais, religiosos, estéticos e de gênero. $\mathrm{O}$ debate sobre as relações étnico-raciais e as infâncias, nos levou a refletir sobre a identidade da criança negra, enquanto uma infância silenciada na Educação Infantil. Os estudos de Abramowicz et al. (2012) 
afirmam que as crianças, aproximadamente, a partir dos 4-5 anos já apresentam algum tipo de conceito ou identificação racial. Além de pontuar as tensões nos processos identitários que orientam as políticas de reconhecimento, enquanto possibilidade de ressignificar as diferenças.

A Lei 10.639/03 que altera a LDB representa um avanço significativo das reivindicações do movimento negro na educação ao tornarem obrigatório o ensino da temática étnico-racial e indígena nos ensino fundamental e médio e favorecem a política de reconhecimento das relações raciais. "Não por acaso, essa Lei se restringe especificamente às escolas de ensino fundamental e médio: a educação infantil foi excluída: trata-se de desenlace de longo percurso histórico" (Rosemberg, 2012, p. 33). Nesta direção, quais seriam as boas estratégias para fortalecer as identidades negras entre os adultos, para que possam educar no campo das relações étnico-raciais? E como as crianças se veem e são vistas pelas outras crianças?

\section{Contextos significativos para pensar a diversidade}

Este trabalho tem por objetivo identificar as estratégias adotadas na prática docente em Educação Infantil acerca da Educação das Relações Étnico-raciais na escola na perspectiva de Lei 10.639/2003. Para este estudo, optamos por uma abordagem qualitativa de pesquisa com observação participativa, fotografias e registro das narrativas das crianças e suas agendas e no caderno de planejamento dos professores. O estudo foi desenvolvido a partir das observações de crianças entre 4-5 anos em uma unidade universitária de educação infantil, a Escola de Educação Infantil da Universidade Federal do Rio de Janeiro (EEI-UFRJ). As atividades envolveram as professoras, a participação das crianças e seus familiares, em eventos distintos, em uma oficina destinada aos adultos durante a jornada pedagógica na escola.

Os professores estavam em processo de observação das crianças para pensar outras possibilidades de atividades e propostas de trabalho que partissem dos seus interesses. Optamos por uma escolha alheatória de nomes para que as crianças não sejam identificadas. O grupo observado se constitui por 15 crianças e 4 professores que se organizam em duplas pela manhã e a tarde para que o mesmo seja atendido em tempo integral. A cena a seguir se passa no refeitório da Escola de Educação Infantil da Universidade Federal do Rio de Janeiro (EEI-UFRJ).

Um pequeno grupo de meninas estava planejando o banho, Naomi e Lucy ouviam atentamente as proposições de Lili que definia quem iria tomar banho com ela, uma vez que elas costumam se organizar também com esta finalidade sobre a observação atenta dos professores.

E Lili dizia: "quem vai tomar banho comigo tem cabelo liso... Naomi que, aos quatro anos alisa os seus cabelos crespos longos e faz questão de usar uma toca durante a chuveirada, para não desfazer a prancha, muito bem orientada por sua mãe que também os alisa. E, já tem toda uma rotina de cabeleireiro como gente grande! Naomi jogou o cabelo e disse: Eu tenho o cabelo liso! Certa que era a escolhida... $\mathrm{E}$ Lili continuou, mas tem o cabelo liso e curto... direcionando o olhar para Lucy que se sentiu escolhida enquanto Naomi, preterida. A esse respeito, recorremos à análise de Fúlvia Rosemberg para compreendermos que: 
"A maioria (ou a quase totalidade) das pesquisas que observaram ou escutaram crianças e apreenderam vocabulário, classificação, preconceito e hostilidade raciais foram realizadas nas regiões Sudeste e Sul, sendo poucos os trabalhos realizados em regióes, estados, municípios ou escolas em que a população negra é majoritária. Além disso, os trabalhos têm pouco se preocupado com esta dimensão, como se essas condições do contexto não tivessem impacto em manifestações simbólicas do racismo" (ROSEMBERG, 2012, p.40).

"Mesmo na faixa etária a partir de 4 anos de idade, as pesquisas na área de educação infantil já apontam a existência da problemática racial entre crianças e adultos, sendo que esses últimos acabam utilizando práticas cotidianas que podem até mesmo reforçar o racismo, levando as crianças negras a um processo de socialização diferente da criança branca" (p. 54).

Lili exerce uma liderança natural sobre as meninas do grupo e curiosamente apresenta um repertório cultural sobre o tema interessante, de acordo com o relato dela mesma na roda de conversas, ela afirma que "a minha mãe é branquinha e o meu pai é pretinho". E você Lili? Disse o professor. "Sou branquinha igual minha mãe...”.

A situação no refeitório revela o impacto das manifestações simbólicas do racismo apontadas por Fúlvia Rosemberg. Assim como a dedicação de Naomi para ser reconhecida no grupo reafirma o processo de socialização presente nas práticas cotidianas entre as crianças que podem levar ao racismo (ROSEMBERG \& OLIVEIRA, 2012).

Entendemos que o "mal-estar" provocado pela questão relativa ao alisamento do cabelo passaria despercebido se a professora não se sentisse encorajada e em condições de pensar uma estratégia de mediação que favoreça a autoestima das crianças e o caso não seja silenciado.

A partir desse contexto, os professores decidiram discutir a temática identidade e diferença para realizar atividades explorando a literatura infantil e as artes como potência para favorecer o debate e autoestima das crianças, como estratégia de proporcionar experiências positivas para o desenvolvimento pleno da criança negra.

Um dos professores assumiu a iniciativa de perguntar sutilmente às famílias se as meninas observadas tinham bonecas negras. E ficou evidente que não tinham ou quando muito tem uma que fica em segundo plano. A intervenção se deu sobre o pretexto de que não tínhamos bonecas negras na sala e estaríamos aceitando doações.

Uma das mães atendeu ao pedido, fez uma doação e entregou a professora da tarde, pelas redes sociais (in box), uma estratégia que utilizamos para a informação sobre o grupo circule entre os professores com agilidade, a professora perguntou: Professor, você pediu para mãe da Naomi trazer bonecas para escola, por quê? Para ficar na sala e as crianças brincarem com bonecas negras, disse o professor. Mas nós não temos um projeto... Disse ela. Verdade, mas não planejamos que íamos discutir identidade e diferença? Perguntei a algumas mães se elas tinham bonecas negras em casa e se poderiam doar uma à escola. Hummm! Murmurou a professora.

O diálogo revelou que os professores não tinham clareza acerca das possibilidades que a temática abrangia. E optamos por organizar uma oficina de máscaras africanas para os adultos, professores e famílias na jornada pedagógica da escola. A oficina escolheu a obra de Pablo Picasso para iniciar o trabalho, considerando que:

"As tradições africanas, como as máscaras, combinam produçôes de caráter mais realista e outra de natureza mais abstrata e por isso essas tradiçôes não devem ser vistas com foco na religião. 


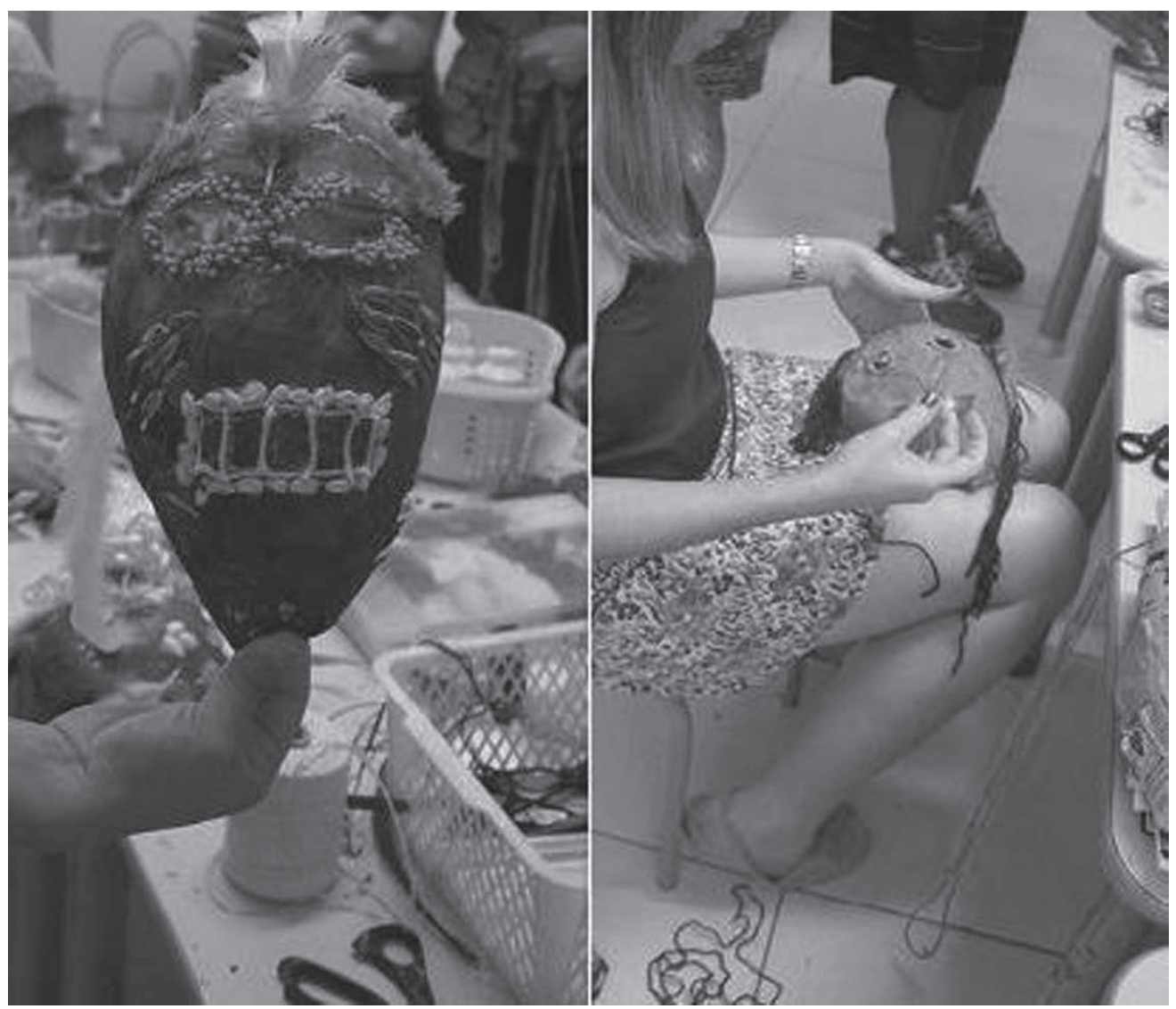

Oficina de máscaras com as famílias e professoras

A tendência é uma visão que permita uma abordagem multidimensional das representações e interpretações (...). A estética africana pressupóe uma unidade de meios complementares. Ou seja, essas máscaras africanas se combinam à música è dança para atingirem seu significado pleno. Uma máscara precisa ser dançada, precisa dançar. Diante disso, trabalhar com elas pode trazer desdobramentos para as crianças sobre questões tão pertinentes à educação quanto os modos de ver, perceber, receber o outro". (ALCANTARA et al, 2014, pp.2-3).

Outra observação do grupo foi à preocupação com as famílias acerca das implicações religiosas sobre o trabalho com máscaras africanas, mas os professores entenderam que este é um tema que não está previstos entre os objetivos da oficina, mas se grupo apresentasse algum interesse, poderíamos explorar, portanto, nesse trabalho privilegiou-se as dimensões éticas e estéticas das tradições africanas a partir da obra de Pablo Picasso. "Se tomarmos, por exemplo, a função social da criança africana, ali a noção de individuo não tem valor por si só. $\mathrm{O}$ individuo não tem existência própria, ele existe em função da sociedade" (ABRAMOWCZ \& OLIVEIRA, 2012, p. 34).

Nesse sentido, nos interessa compreender qual o papel dos adultos enquanto professores e familiares sobre as possibilidade de socialização e da negociação dos desejos enquanto sujeitos de direitos. A construção da oficina mobilizou todas as crianças do grupo, que ao longo da semana colheram sementes, cascas e gravetos no pátio, além encherem as bolas e aplicarem jornal com cola, inspirados em papel machê para dar contorno às máscaras e, nas rodas de conversa demonstraram que estavam compreendendo a sua participação, como podemos ver o registro na agenda realizado 
por uma das mães: "O Flávio disse que amanhã não vai ter aula porque os adultos vão fazer máscaras africanas para eles na reunião” (Agenda do Flávio, 07/11/2014).

\section{Considerações finais}

Ao término da oficina, o grupo fez uma roda de conversas para refletir sobre os caminhos para pensar a diversidade com as crianças. Os professores sugeriram a abordagem a partir da literatura infantil brasileira e africana. Propuseram a interlocução com grupos com reflexões sólidas sobre as tradições africanas no Rio de Janeiro. $\mathrm{O}$ grupo foi unânime em considerar a obra de Pablo Picasso selecionada para orientar a oficina destacando as dimensões éticas e estéticas de sua obra e do trabalho coletivo. Alguns professores decidiram doar as máscaras para o grupo que organizou a oficina, outras preferiram levar para os seus próprios grupos.

O estudo evidencia que a discussão é inicial e aponta para a realização de outros eventos que se articule ensino, pesquisa e extensão. Também é importante o envolvimento formativo dos professores para que juntos consigam mediar os conflitos entre as crianças, elas criam situações e repostas para as questões étnico-raciais que aparecem e podem propor soluções críticas e criativas construídas em contextos significativos.

\section{Referências}

ARIÉS, P. História social da criança e da família. Trad. Dora Flaksman. 2. ed. Rio de Janeiro: Livros Técnicos e Científicos, 1981.

ABRAMOWIZ. A. \& OLIVEIRA, Fabiana. As relações étnico-raciais e a sociologia da infância no Brasil: alguns aportes. In. BENTO, Ma Aparecida Silva (org.). Educação infantil, igualdade racial e diversidade: aspectos políticos, jurídicos, conceituais. São Paulo: Centro de Estudos das Relações de Trabalho e Desigualdades - CEERT, 2012.

ALCANTARA, Deise et al. Máscaras Africanas: Identidade/Diferença (Oficina). Rio de Janeiro, Escola de Educação Infantil, UFRJ, 2014.

CAMPOS, M. M.; ROSEMBERG, F.; FERREIRA, I. M. Creches e pré-escolas no Brasil. 2. Ed. São Paulo: Cortez, 1995.

CANCLINI, N. G. Culturas hibridas: estratégias para entrar e sair da modernidade. São Paulo: EDUSP, 2000.

CARVALHO, C. R. e PASSOS. M.C. P. Práticas, narrativas e memórias da diáspora: paisagens de uma pesquisa. 31a Reunião Anual da ANPEd: Caxambu/MG, 2008. Disponível em: http://www.anped.org.br/reunioes/31ra/1trabalho/GT21-4792--Int. pdf. Acesso em: dezembro de 2011.

HALL, E. Da diáspora: identidades e mediaçôes culturais. Org. SOVIK, L. Belo Horizonte: UFMG, 2003.

ROSEMBERG, Fúlvia. A criança pequena e o direito à creche no contexto dos debates sobre infância e relações raciais. In. BENTO, Ma Aparecida Silva (org.). Educação infantil, igualdade racial e diversidade: aspectos politicos, jurídicos, conceituais. São Paulo: Centro de Estudos das Relações de Trabalho e Desigualdades - CEERT, 2012.

BRASIL. Leis e Decretos. Lei de diretrizes e bases da educação nacional: lei n.9.394/1996. Brasília, 1996. 
. Lei no 10.639 de 09 de janeiro de 2003. Inclui a obrigatoriedade da temática "História e Cultura Afro-Brasileira" no currículo oficial da rede de ensino. Diário Oficial da União, Brasília, 2003.

. Lei no 8.069, de 13 de julho de 1990. Dispõe sobre o Estatuto da Criança e do Adolescente.

. Lei $\mathrm{n}^{\mathrm{o}} 11.700$ de 13 de junho de 2008 , garante vaga em escola pública de educação infantil ou de ensino fundamental próxima à residência. Diário Oficial da União, Brasília, DF, jun. 2008.

. Emenda Constitucional No. 53, de 19 de dezembro de 2006.

Dá nova redação aos arts. 7º 23, 30, 206, 208, 211 e 212 da Constituição Federal e ao art. 60 do Ato das Disposições Constitucionais Transitórias. Diário Oficial da União, Brasília, DF, dez. 2006.

. Emenda Constitucional no 59, de 11 de novembro de 2009. Prevê a obrigatoriedade do ensino de quatro a dezessete anos e ampliar a abrangência dos programas suplementares para todas as etapas da educação básica. Diário Oficial da União, Brasília, nov. 2009.

KUHLMANN, Jr. M. Infância e educação infantil: uma abordagem histórica. Porto Alegre: Mediação, 1998. 